\title{
STRENGTHENING SOCIAL STRUCTURES FOR PROTECTING WOMEN'S RIGHTS AMONG THE KASSENA OF NORTHERN GHANA
}

\author{
Judith Bawa \\ Centre for Continuing Education and Interdisciplinary Research, \\ University for Development Studies, \\ Tamale, Ghana \\ Email: judithbawa@gmail.com \\ Doi:10.4314/gjds.v9i1.4
}

\begin{abstract}
Women's human rights abuse has become an issue of global concern. It is estimated that one in three women worldwide has been abused physically, emotionally and psychologically in her lifetime. Evidence on the extent to which socio-cultural structures support the human rights abuse of women or protect against them has been sparse and general. Available data often name and describe various forms of abuse but hardly detail out the specific and structured form of the abuse. Using the Kassena of Northern Ghana as a case study, this paper investigates the incidence of women's human rights abuses among a specific cultural setting. Personal interviews, desk reviews and participant observation methods were used to obtain empirical data for the analyses. Key findings reveal high incidence of women's rights abuse, changing nature of the abuse and factors accounting for the situation. It also reveals that there are some structures, civil and traditional, in place for protecting women but these are weak and ineffective. The paper concludes that in order to protect women's rights among the Kassena, there is the need to adopt an integrated approach, which blends civil and traditional strategies for dealing with the human rights violation of women.
\end{abstract}

KEY DESCRIPTORS: Women`s Human Rights, Cultural Practices, Social Structures, The Kassena, Gender-Based Violence

\section{INTRODUCTION}

According to Amnesty International (2010), living a life free from violence is a human right, but millions of women and girls worldwide suffer immensely from violence both in peace and war time, by the State, at home and in communities. By and large, women are often marginalised and degraded, beaten, raped, mutilated and killed with impunity. This gender-based violence, Amnesty International notes, stems from a failure by governments and society to recognise the human rights of women and a global culture of discrimination which denies women equal rights with men.

The issue of rights violations against women is assuming pandemic proportions. UNIFEM (2000), WHO (2009) and World Bank (1994) have all reported that at least one woman in three worldwide has been beaten, coerced into sex or abused otherwise in her lifetime. The United States (US) Department of Justice also revealed that of the reported 16,000 assault cases in $2010,22.1 \%(3,376)$ of the victims were female. Also, $6 \%(1,260)$ of the 21,000 reported cases of violence by the Home Office of the United Kingdom (UK) were female. This is against the 1999 figures of 1,218 and 400 female victims in the US and UK respectively. WHO (2005) and Amnesty International (2003), among other sources, also report of various forms of violence on women by husbands or other intimate partners in all the regional blocs of Africa.

In Ghana, there are also reports of a rising trend. For example, between January 1999 and December 2002, the then Women and Juvenile Unit (WAJU) of the Ghana Police Service (GPS) recorded 1,869 cases of assault/wife battering alone (WAJU 2003) cited in (Amoakohene 2004). 
In 2009, the now Domestic Violence and Victims Support Unit (DOVVSU) of GPS handled a total of 5,709 cases against 4,904 cases in 2008, an increase of 805 (allafrica.com 2010). UNIFEM (2000) blames some religious practices for many of the rights abuses that women suffer in parts of the world with typical cases being the norms prescribed for women. Analysts however argue that the increasing trend could be attributed to the emboldening of victims by a more vigorous sensitisation and education as well as increased media reportage on the issue and disregard of social stigma attached to those who speak up when abused. Some experts view violence against women as a symptom of the historical unequal power relations that exist between men and women. WHO (2009) also explains that before the 1970s, violence against women was viewed by experts as a private matter to be resolved among individuals. However, the situation changed when it was recognized as a human rights violation from the late 1970s to 1980 s and beyond.

Tomasevski (1991) argued that even though women's rights issues came to global attention only in the 1970s, the struggle for equal rights by women dates back to the 1780s. In 1946, a Commission of the United Nations (UN) was created to formally bring to global attention the situation of women. Consequently, the period from 1975 to 1985 was declared a "Decade for Women" as part of efforts to remedy the situation of women and to integrate them into the development agenda. Conferences, including the 1980 one in Copenhagen, 1985 in Nairobi, 1993 in Vienna and 1995 in Beijing have all focused on women's strategic gender needs through direct state intervention in order to reduce gender inequality and enhance women's rights. The idea of women's human rights was a framework for women to articulate and collaborate around broad and similar concerns about the status of women. It also provided women with a way to elaborate on the most pressing human rights issues specific to particular political, geographic, economic and cultural contexts.

A 1996 - 2000 UN conference report notes that by the time of the Vienna Conference of 1993, the idea that women's rights are human rights had become the rallying call of thousands of people all over the world, and one of the most discussed "new" human rights debates. It adds that the Vienna Declaration and Program of Action that was outlined was meant to signal the agreement of the international community on the status of women`s human rights (UN, 2000). Ghana has signed on to the African Charter on Human and Women`s Rights, and participates in the African Platform for Action (PFA). By the establishment in 1975 of a national machinery in the form of a National Council on Women and Development (NCWD) and the creation of a Ministry for Women and Children Affairs (MOVAC) in 2001, Ghana has demonstrated her commitment for a society in which every member`s right is respected although cases of women's rights abuse remain widespread. On a daily basis, mass media reports of violence of various forms including murder, rape, defilement, beating and arson attacks (Osam, 2004). This also supports the work of the DOVVSU5, which since its establishment, has consistently documents regional and national reports on domestic violence. Such reports show that women`s rights abuses are on the rise in Ghana.

In the Kassena area of northern Ghana, both the media and DOVVSU report of various forms of violations ranging from child maintenance through battery to sex abuse. The frequency of such reports especially in the media gives indication of a rising trend. Among the broader population, the abuses which border on human rights range from the battering of wives by husbands and boyfriends, humiliating rites of passage and widowhood rites to the prevention of women from participating in some activities due to cultural barriers. It is also the case that beyond the formal structures of the state, traditionally there have also been social structures by communities and society to guard the rights all. However, the extent to which these structures, formal and traditional have worked to protect the rights of women in particular has been contested (Apusigah, 2004, Abantu, 2004). In the case of formal provisions, weak designs and

\footnotetext{
${ }^{5}$ DOVVSU, the Domestic Violence Victims Support Unit, as an agency of the Ghana Police Service, which was reconstituted in 2004/05 from the erstwhile Women and Juvenile Unit (WAJU), which was established in 1998.
} 
implementation defects of the structures have been cited for perpetuating women's rights abuse (Abantu, 2004; Dwamena-Aboagye, 2004).

The thesis of this paper is that these structures need to be strengthened and merged to make them more effective in empowering the victims and to claim their rights within the law. This is drawn from the Narayan Empowerment Theory which focuses on empowering state and civil institutions at both local and national levels including formal institutions such as kinship and neighbourhood networks to make them work. Institutions such as marriage and the household are not considered part of the State or Civil society, but inter-personal gender dynamics are considered part of the equation of social exclusion and in need of direct efforts at change (Narayan et. al, 2000a).

The paper investigates the nature and extent of women's human rights abuse, the trends and effects, measures in place to protect women and the effectiveness of these structures. It makes a case for developing a multi-strategy approach that harnesses the strength of formal and informal structure, for dealing with the situation and makes recommendations for adopting some measures that could help curb the rights abuse of women. However, it focuses only on the human rights abuses of women within the family and the community. The Kassena were chosen for the study because the subject is a sensitive one and women feel uncomfortable to talk about it and especially so to a stranger. As a native and a woman, the women felt comfortable talking to me about their situation.

\section{METHODS}

\section{Approach}

A multi-stage approach to data collection was adopted for the study. Personal, semi-structured interviews were held with 60 individuals from Paga and Navrongo comprising 20 women and 10 men from each locality with the aged and young, educated, and uneducated, Christian and non-Christian as the variables. Purposeful sampling was adopted in choosing the two towns and the category of persons interviewed. Navrongo is more urban than other Kassem-speaking communities and had contact with formal education earlier than the others while Paga is more rural but has more varied ethnic population due to its position as a border town between Ghana and Burkina Faso. Secondary data was sourced from desk reviews and previous works on the subject and study area.

\section{Demographic characteristics}

Of the 60 respondents, 40 were female and 20 male with age ranges of 28 years and 75 and above years. That is to say, 25 respondents were between ages 28 and 34 while 30 fell between ages 35 and 50 and 5 were 61 years and older. 30 respondents had formal education with the highest attainment level of primary six and the highest level Cert " $\mathrm{A}$ " Teachers certificate. Also, five (5) of them had non-formal education and 15 of them have not had formal education. The occupational distribution consists of 5 retired teachers, 15 Civil and Public servants, 34 were traders and 6 were unemployed.

\section{Area of Study}

The Kassena are located in the Upper East Region of Ghana and in southern Burkina Faso. Together with their neighbours of the Nankani ethnic group, they form the Kassena- Nankana East and Kassena- Nankana West Districts of the Upper East Region. The principal towns of the Kassena in Ghana are Navrongo, Paga and Chiana. They are estimated to be about 77, 954.1 Kassena in Ghana; 48.4\% of whom are male and 51.6\% female (GSS, 2010). Apart from the slight dialectical differences, the three towns have a lot in common culturally and socially. 
Marriages are potentially polygamous and the extended family system is valued (Howell, 1997) as it tends to influence matters relating to family life.

\section{UNDERSTANDING WOMEN'S RIGHTS AS HUMAN RIGHTS}

\section{Conceptualizing human rights and women's rights}

Human Rights are the fundamental rights that all humans have by virtue of being human beings and citizens of the world community. Human beings are born with equal and inalienable rights as set out in the fundamental freedoms of the UN Universal Declarations of Human Rights, which recognise the individual and groups rights as well as freedoms, justice and peace for all in the world (UN, 1948). The principle of universality of human rights is the cornerstone of international human rights law which applies equally to every human being regardless of gender, ethnicity, race or colour. Human Rights are indivisible, interrelated and interdependent, such that the improvement of one facilitates the advancement of the other just as the deprivation of one adversely affects others. Consequently, Governments, institutions, intergovernmental and non-governmental organizations are urged to intensify their efforts in protecting and promoting the human rights of women and girls.

Proposals issued from the 1993 Vienna and 1995 Beijing conferences recognise and declare that the human rights of women and girls are inalienable, integral and an indivisible part of the universal human rights. As well, they advocate for the full and equal participation of women in political, civil, economic, social and cultural life, at the national, regional and international levels as well as the eradication of all forms of discrimination on grounds of sex. Gender-based violence and all forms of sexual harassment and exploitation, including those resulting from cultural prejudice and international trafficking are incompatible with the dignity and worth of the human person and as such must be eliminated.

The 1995 Beijing conference on women recognised that gains had been made in the improvement of the status of women but noted that inequalities and obstacles still remain. It therefore reaffirmed its commitment to the struggle to promote the equal rights of women and the girls; the advancement, empowerment and full participation of women and, believed to be fundamental to equality, development and peace. Current development discourses also recognise that gender equality is a basic human right, with value in and of itself and the centrality of gender issues to the attainment of development as many disparities in development outcomes arise from gender differences (Vijayamohanan et. al., 2011). Abantu for Development (2004) has also lamented that in spite of laws and instruments protecting women's rights such as the Marriage Act (1884 - 1985), Intestate Succession Law PNDC Law 111 (1985), Customary Law, the Labour Act 651 (2003) and the Criminal Code (1965, 1985, 1991) have been passed to protect women, gender inequality gaps remain wide. The laws and instruments make clear provisions for improving the status of women, although women continue to suffer bias, discrimination and abuse in Ghanaian societies.

Tradition, prejudice, social, economic and political interests have combined to exclude women from the prevailing definitions of "general" human rights and to relegate them to secondary and/or "special interest" status within human rights considerations (Amnesty International, 2010). Gender discrimination is still prevalent in all areas of life. For example, women still suffer from honour killings, dowry deaths, widowhood rites, rape, acid attacks, selective abortions, infanticide and forced marriages. As well, gender parity in governance is still a major issue and in some jobs, women are paid less for same work done as men (WHO, 2005; Amnesty International, 2010). Bunch and Frost (2000) see these worldwide human rights violations as a reflection of gender inequality in the world at large. They argue that the situation has formidable impacts on women's lives. 


\section{Women's Rights Violations in Ghana}

The Human Rights Report of Ghana (2009) identified domestic violence such as rape and defilement, wife battery, male dominance and intimidation, discrimination on the basis of gender and social status, cultural and religious practices such as female genital mutilation (FGM), widowhood rites and forced marriages, as some of the rights abuses that Ghanaian women suffer. Trokosi, a practice that enslaves young virgins to life-long servitude for crimes committed by relatives, for example, violates their fundamental rights to be free. Nukunya, (2003) observes that wife and child beating is a common means of punishment in Africa and Cassiman (2006) confirms that Kassena women have been socialised to accept beating within marriage as normal. These abuses are mostly borne in silence by the victims, who may also blame themselves for the violence meted out to them. The results of this are scaring, deformities, physical and emotional trauma, loss of self-esteem and depression can be tragic leading to long term psychological effects or death, with high economic implications (Amnesty International, 2005).

Campaigns by human rights and other concerned groups advocating for the protection of women's rights have heightened awareness and the intensification of efforts to curb the menace. Rahman and Toubia (2000, 2004), Lithur, (2004) and Dwamena- Aboagye (2004) have all advocated for legal action against perpetrators of women`s human right abuses as a measure by governments to ameliorate the situation. However, culturally, issues such as abuse within marriage are considered a private matter and each society deals with them based on its norms and values, which aim at protecting the sanctity of marriage. These protective measures have largely not been effective due to various factors considered structural as will be demonstrated below.

\section{INCIDENCE OF WOMEN'S HUMAN RIGHTS ABUSE IN THE KASSENA AREA}

The findings from the empirical study among the Kassena indicate that while some of the human rights abuses such as wife battery, male dominance, intimidation, widowhood rites, neglect of family and restrictions on movement and on some foods are on the rise other practices such as FGM, levirate and eloped marriages and to some extent widowhood rites are on the decline. The respondents attributed the emerging trend to formal education, advocacy, sensitisation, Christianity and urbanisation.

All the respondents attested to the fact that social structures such as family and kinship relationships do protect women but economic and other considerations have compromised them. These days, they explained, when a man dies, the family immediately demands for his property without considering the welfare of the widow and children. In a ploy to alienate her, the woman could be accused of culpability in her husband's death and hence excluded from decisions relating to her husband's funeral and estate. That trend was said to be alien to the Kassena, who traditionally should seek to protect the widow and children. Among them the first and right thing is to ensure the comfort and care of the widow and children.

\section{Wife Battery}

All $40(100 \%)$ of the female respondents and $5(25 \%)$ of the male respondents admitted that wife battery and wife and child neglect, male dominance and wife intimidation are on the increase. This was attributed to frustration due to economic hardships, alcoholism, hard drugs, peer influence and disregard for the cultural values of the Kassena. While the older respondents attributed the situation to disregard of the youth for societal norms when marrying, the younger male respondents attributed it to the refusal of wives to obey and submit themselves to their husbands. 
All the female respondents confirmed that men in Kessengo dominate women and try to intimidate their wives when they feel threatened by their boldness and hence use battery to get at them. Sometimes, they said, the men refuse to fulfil their responsibilities of providing for family care and maintenance needs and when the woman complains, she is hit. It was also explained that even those men who live up to their responsibilities use it to control their wives. The men on the other hand blame some of the women for trying to assume the role of the man when they become economically independent. The older women however say that it is natural for men to dominate women because by paying the bride price, they own them, so when they submit, the men will respond with love. This exemplifies arguments raised by Apusigah (2004) regarding distortions on the question of ownership and its mis/applications regarding women's rights in the family.

\section{Neglect}

Wife and child neglect is another phenomenon that is assuming alarming proportions in the study area as indicated by $60 \%$ of the respondents which they attribute to poverty, irresponsibility and drugs. The older respondents attribute the situation to inexperience on the part of the youth who hurriedly go into marriage when they are not economically independent. In majority of these cases, the couple are in live-in relationships due to an unplanned pregnancy or the refusal of the family to acknowledge the relationship, even though a considerable proportion of it is with normal married situations. A female respondent complained of her husband of over 18 years who abandoned her and two of her three children in the village while he domiciled in the south without sending them any remittances. She had to do some menial jobs to take care of herself and her children.

Also, $67 \%$ of the respondents confirmed that women still go through widowhood rites, with the practice being popular with older compared to younger women. Christianity and Islam among other influences were assigned for contributing to its relaxation. Younger women complained of the undignified way their nudity is exposed and the health hazards that result from the experience.

All respondents indicated that there was a steep decline in the practice of FGM in Navrongo with the only confirmed new cases recorded in Paga, which they explained, are done secretly. They attributed this to the work of the Navrongo Health Research Centre (NHRC), formal education, Christianity and formal education. The fear of prosecution has also played a major role in the reduction of the practice in the area.

In addition, $80 \%$ of the respondents indicated that forced and levirate marriages were not as common as they used to be but it was still practiced. In cases where the widow who has young children but does not have any means of income generation or support she might opt to marry a relative of the husband in order to enjoy his protection and support.

On the restriction of movements for widows and restriction of women from eating certain categories of food, the responses were mixed. While some (33\%) said these restrictions were relaxed, 50\% said it was still practiced. However, because the restrictions affect women's income generation activities, they are often allowed to go out after the mandatory mourning period is over and the restriction of movement is relaxed. Urbanism and formal education have also diminished the psychological and religious effects of eating some kinds of meats. In the study, $25(63 \%)$ of the female and $10(50 \%)$ of the male respondents confirmed this.

All respondents however affirmed that the breakdown of the extended family system is affecting many aspects of life. The value of belonging, the moral and other forms of support derived from it have weakened the family. This was attributed to problems that families and communities experience. 


\section{Cultural Practices}

\section{Rites of Passage}

Rites such as FGM, forced marriages, funeral and widowhood rites have both positive and negative effects on victims but due to their socio-cultural significance, some girls and women still undergo them despite the health implications and legislative and legal provisions made to end them. Societies will also try to perpetuate such practices in order to maintain their norms and values even if it means doing so secretly. This confirms Feldman-Jacobs and associates (2006), and Wandia's, (2009) assertion that such issues need more than just legislation and legal frameworks. They explain that the enforcement of and court mechanism need to be friendly and accessible to women. Communities also need to be assured that eliminating such practices will not promote foreign values. Apusigah and Opare (2007), NHRC (2004), Rahman and Toubia (2000) and other sources suggest a combined strategy of educating communities, opinion leaders and women on the harmful effects and legal implication of such practices and to empower them economically and legally with the view to eliminating them. They also suggest the provision of alternative livelihood options for the practitioners.

\section{Forced marriages}

Eloped and other forms of coercive relationships such as levirate marriages represent a denial of women of the right to a mutual agreement on choice of partner as provided for in Article 6 Clause E of the African Charter on Human and Women`s Rights. This practice reveals the level of male dominance over women. The setting up of gender desks in MMDAs and of DOVVSU have helped to improve responses to and the reporting of rights abuses of women in the communities, but has not completely routed it out. There are still women whose rights to choose a partner are being violated. Experts agree that education is crucial in changing social attitudes that perceive women as inferior or as properties of their spouses and so can be illtreated by them without apologies (UNIFEM, 2005). In the same breadth, abusive men need to understand that as per the human rights provisions, no human being has the right over another person even if that person is a dependent. Both men and women also need to understand that communities gain when women are protected, and this can be achieved through advocacy.

\section{Bride wealth}

Bride wealth (price), according to (Howell 1997; Cassiman, 2006) is part of the package that validates the marriage contract among the Kassena. Cultural values and norms are important for the survival of society, but when they violate human rights, they need to be reviewed and revised. Women's rights activists such as the Women`s Manifesto Coalition of Ghana and the Ghana Association for the Welfare of Women have called for the abolition of bride price as a means of protecting women but it is also important to recognise its social and cultural significance as a basis for seeking mutual respect between and among spouses. Sensitisation and legal education for the youth, parents, and community and opinion leaders can help to protect women. This can be achieved through sensitisation during festive occasions and incorporation into school curricula. Recognition of the social and legal structures by all stakeholders, empowering them and holding them responsible for lapses can be considered.

Above all, Article 2, Clause B of the African Charter on Human and Women rights called for the elimination of discriminatory practices against women especially those that are deemed harmful to and endanger the health and general well-being of women. 


\section{STRATEGIZING TO END WOMEN'S RIGHTS VIOLATIONS}

\section{Formal Strategies}

\section{Laws and Legislation on Women Rights}

In spite of signing on to the various conventions, such as CEDAW, and the enactment of laws and legislations in Ghana, women continue to suffer human rights violations, as they prove to be ineffective in combating or curbing violence against women (Dwamena-Aboagye, 2004). This situation could be attributed to the weaknesses of law enforcement agencies in dealing with matters relating to customary law and their failure to understand and to include culturally appropriate dimensions in their strategies and to work with culture to review outmoded meanings, while drawing on the positive aspects of culture to protect women. For instance, modernisation with its materialism has led to distortions of culture in ways that commercialise rather than revere women thereby devaluing them (Apusigah, 2004).

The Criminal Code of Ghana (1960) for example criminalises FGM, but the NHRC (2004) argues that criminalisation has forced the practice underground rather than end it because due to its cultural, social and religious significance, girls in rural areas tend to present themselves for it. As such, criminalising the practice becomes a dangerous measure because victims who suffer complications during the process may for fear of exposure and prosecution die without receiving any treatment from a health facility. The fear of societal rejection also causes women to accept abuses quietly because those who speak up often lose their marriage. In society where marriage is perceived to give women status, there is the tendency to do anything and everything to stay in marriage. For this reason, Martin and Hashi (1992) recommend that enacted laws should be relevant to the needs of the people they are meant to serve otherwise they become useless.

\section{Civil Laws}

Civil laws are promulgated by states to protect and govern the conduct of citizens in civil relationships. The effectiveness of these laws are however doubtful due to challenges in enforcement, weak instruments or inappropriate training of the law enforcement agencies on how to deal with issues regarding the rights abuses of women. These laws are not always fully understood by some of the people they are set out to protect or are considered foreign and so the people do not feel obliged to obey them. Consequently, when conflicts arise within the family or community the people ignore the law and settle issues in ways they know best, thereby abusing the rights of others.

The law requires that a victim of abuse should report the case to the law enforcement agencies for redress and when found guilty, the offender should be punished either by a fine, a term of imprisonment or both. This requirement does not always solve the problems of the victims (and their children). In Northern Ghana, for example, it is culturally unacceptable for a wife to report her husband to the law. Doing so is interpreted as a disregard of the kinship and family systems, whose function include arbitrating on such matters. Hence, any perception of breech can attract suspicion and/or scorn from family members including fellow women and could lead to the dissolution of the marriage. For those women who depend on their husbands for financial and social support, they have no option but stay in silence while the abuse is repeated. Since Ghana practices a plural legal system that accommodates customary, religious and statutory laws, enforcement agencies need holistic training on the formal and informal systems so as to be better equipped to handle such cases and through that an effective legal system that can protect women and the vulnerable in society would evolve. Martin and Hashi (1992) note that by simply writing or rewriting laws in the statute books, one does not necessarily address the sociocultural, political and administrative issues that need redress. 


\section{Management Structures}

It is in its attempt to address the weaknesses of the ineffective structures that the NCWD and WAJU now DOVVSU, were established by the government. The MOWAC and gender desks in the governance structure nationally and locally have also been instituted and tasked to initiate programmes and activities that will help reduce the incidence of rights abuses against women with emphasis on training and education for all key players such as law enforcement agencies as well as victims and offenders on domestic violence. Ministries, Departments and Agencies (MDAs) such as the Ministry of Health (MOH), the Department of Social Welfare and some civil society organisations have also been tasked to incorporate programmes and strategies into their activities and to provide shelter for victims.

\section{Advocacy and Education}

Programmes and strategies aimed at enhancing women`s development have been put in place nationwide in the quest to fight the rights abuses of women. The creation of DOVVSU and establishment of gender desks in all the Municipal, Metropolitan and District Assemblies (MMDAs) have boosted the resolve to fight gender discrimination. The Criminal Code criminalises harmful cultural practises such as Trokosi, FGM and abuses such as rape, defilement, incest, forced marriages and elopement and recommends stiff punishment for perpetrators. The 1992 Constitution guarantees the rights of individuals while the MDAs design strategies and activities on education, advocacy, capacity-building of key players and provision of material and emotional support to victims of human rights abuse. Political interferences and poor resourcing have however negated the effectiveness of these strategies. In some cases, mandates have been duplicated and thereby limiting ability to achieve desired results (Tsikata, 2000; Apusigah \& Opare, 2007).

The Domestic Violence Bill was passed by the Ghanaian Parliament in 2007 with the charge to initiate outreach and awareness creation programmes under the Protective Model of the Community Policing programme. Public seminars and radio talk shows are also being held nationwide as a way of protecting women and children from abuse. Civil society organisations (CSOs), Non-governmental Organisations (NGOs) and Community-Based Organisations (CBO) are in the forefront of education, sensitisation and advocacy programmes on women's rights abuses in communities.

\section{Informal Strategies}

\section{Social Structures}

Social structures have evolved as a means by which relationships are expressed with women as mothers, wives, sisters or aunts and ensuring that women are respected and treated well. Some of these structures include but are not limited to marriage systems (including contractual procedures), kinship relationships and extended family systems. Ironically, some of these same structures are misinterpreted by some members of the society to abuse women's rights. In Ghana, family life, for example, is communal and marriages are social contracts between families and not just the individuals involved. The procedures involved in taking a wife thus demand the full involvement of both families (Nukunya, 2003; Gyekye, 2004; Dolphynne, 1991; Cassiman, 2006). This is meant to empower the extended family system in dealing with family matters and also to offer protection to family members, but when misused, they can be controlling. One example of the controlling aspect of the kinship relationship is in the practice where a widow is compelled to marry from the deceased's family otherwise she loses her right to spousal property. This measure has been meant to ensure that a widow is adequately provided for and protected by the extended family. 
The extended family system offers some checks to ensure the wellbeing of each member, and these checks are embedded in the procedures which the Kassena, for instance, adopt in dealing with conflicts between spouses. For example, when a report of abuse is made by a wife against her husband for example, a mother-in-law, the closest family member, is expected to intervene to resolve the problem. To assure the woman of family support and protection, the man is blamed outright before even hearing him out. When this fails, the head of the family is involved until the family options are exhausted. She is allowed to take the matter to any authority of her choice within the community before she can take it to her family. Kassena norms give the woman the right to opt out of the marriage if she is unhappy in it (Cassiman, 2006), but this has to be procedural. This practice is however gradually losing its usefulness as individualism is fast becoming the norm especially in the urban areas and amid sweeping globalization and modernization.

Gyekye (1996) argues that the concept of human rights in traditional Africa is a cultural, moral and political value, but modernisation has influenced the value system of people in ways that negate this value. For example, the younger generation do not respect the traditions that had held society together and facilitated peaceful co-existence in the past. A rise in social status for some also creates a feeling of superiority over other family members and this undermines the authority of kinship and extended family systems. The breakdown of communal values is also manifest in family disintegration and heightening individualism. For example, in 2010, a woman was reported to have killed all her five children and committed suicide because she felt her husband and family members had abandoned her (Daily Graphic 2010). This might be an extreme case but it brings to the fore how much individualism has weakened the kinship system in protecting its members, which has been blamed on modernity. Ironically, modernisation is about improvement in the lives of people.

In urban areas, economic, social and other pressures have kept parents away from home for most of the time and so deny the children the opportunity to learn the moral and social values of their societies from their parents. Within the primary communities, the younger generation are perceived to be influenced by modernity and are thus likely to display negative attitudes toward their socio-cultural systems and practices. Nevertheless, modernisation is helpful when through formal education and training women's self-esteem is boosted and/or when they are economically empowered through income generation and advocacy initiatives that enhance their negotiative power in relationships and help to better their conditions. The right to education could also ensure that women understand basic civil laws and their rights within them, how to access them and the sanctions applied to breaking them. This will help them to demand their rights or seek redress when abused.

Undoubtedly, it is the workings of the two sources of strategies that have served to change the current trends in women's human rights violations. In spite of each of their weakness, they each have strengths, which when combined, would complement and strengthen on-going advocacy on women's human rights in the Kassena area.

\section{CONCLUSION}

Even though some of the rights abuses such as FGM, widowhood rites and forced marriages are declining among the Kassena, wife battery, wife and child neglect, male dominance and wife intimidation are on the rise which poses a concern. The situation has been attributed to social, cultural and economic factors. There is a dual system of governance that people generally recognise and accept, i.e., traditional and the westernised systems. These systems have instituted structures to deal with human and women`s rights issues. These are however weak and ineffective, because they have been influenced by patriarchal and male-biased. Also, the ineffective training and law enforcement regarding civil laws have also weakened their ability to deal with the situation. This paper recognises both the strengths and weaknesses of traditional 
and conventional systems and hence advocates a hybrid (an integrated) system that builds on the individual strengths and yet redresses their weaknesses in a manner that is complementary, effective and acceptable. It is an advocacy for the scrapping of those negative aspects of the culture which oppress women while strengthening the positive aspects. When this is done effectively, progress will be made in the protection of the rights of women.

\section{RECOMMENDATIONS}

\section{Empowering the key players}

Key players such as traditional authorities, law enforcement agencies, and community and opinion leader should be empowered through advocacy, sensitisation education, and training and networking to help create awareness in communities to facilitate effectiveness

\section{Dialogue}

Continued and sustained dialogue among the various stakeholders; legislators, law enforcement agencies, legal practitioners, traditional authorities, women leaders and civil society on the issue of rights abuses of women needs to be encouraged.

\section{Commitment}

It is important that all the key players work together and with logistics and support from governments to end abuse against women. This would ensure a safe environment for women where they can live in freedom and take their rightful place in society and that the rights of the individual are respected and the vulnerable protected in society.

\section{REFERENCES}

Amnesty International (2003). “Stop violence against women"[online]. Available: http//www.amnesty.org.en/campaigns/stop-violence-against-women DA: 12/09/2009

Amnesty International (2009). Violence against women information." [online]. Available: http//www.amnesty.usa.org/.../women/violence-against-women/v DA: $15 / 02 / 2012$ from

Amparo, T. (2005). A human rights approach to development; primer for Development practitioners, UNDP[online]. Available: http//www.unifem.org.in/PDF/RBA. DA: $13 / 02 / 2012$

Apusigah, A. A. (2004). "Indigenous cultural systems and the rights of women and girls in the Upper East Region of Ghana." A research report submitted to Action Aid Ghana (Unpublished)

Apusigah, A. A. and Opare, J. (2007). “Ghana multi-sector gender profile.” Report submitted to the African Development Bank (Unpublished)

Bunch, C. and Frost, S. (2000). "Women`s human rights: An introduction." (Routledge international encyclopaedia of women: Global women`s issues and knowledge"[online]. Available: http//www.cwgh.rutgers.edu/globalcenter/whr.hlml DA: 15/ 09/ 2009

Cassiman, A. (2006). Stirring life: Women's paths and places among the Kassena of Northern Ghana. Belgium: UniversitaireStitchting.

Dolphyne, A. F. (1991). The emancipation of women: An African perspective.Accra: 
Ghana Universities Press.

Dwamena-Aboagye, A. and Fiamanya, S. D (1999). Combating domestic violence: Love should not hurt. Accra: The Ark Foundation, Ghana

Feldman-Jacobs, C and Ryniak, S (2006). "Abandoning female genital mutilation/cutting: An indepth look at promising practices." Population Reference Bureau. A report submitted to USAID

Gelles, J, (2009). “Dowry.” Microsoft@student (DVD). Retrieved 12/09 / 2009 from

Redmond W.A; Microsoft Corporation,

Ghana Statistical Service (2002). 2000 Population and Housing Census. Accra: Government of Ghana

Gobah, T. and Attram, M. (2010 January 7th). "Killer-mother poisoned five children with parazon." Daily Graphic: 1-3

Gyekye, K. (1996). African cultural values: An Introduction__Accra: Sankofa Publishing Company.

Howell, A.M. (2004). The religious itinerary of a Ghanaian people: The Kassena and the Christian Gospel. Achimota, Accra: African Christian Press,

Kimani, M, (2007, July). "Taking on violence against women in Africa: International norms, local activism start to alter laws, attitudes." African Renewal, 21 (2)[online]. Available: http//www.un.org/en/africarenewal/vol2/212-

violence-against-women.html DA: 16/09/2009

Lithur, 0. (2001). "Assessing Gender and Political Power in Ghana.", In Ghana Academy of Arts and Sciences (ed.). Gender: Evolving Roles and Perceptions. $(64-65)$. Accra: $\quad$ Black Mask Limited.

Martin, D. M. and Hashi, F.O. (1992). "Women in development, the legal issues in Sub-Saharan Africa today." (Working Paper No. 4), The World Bank, Washington D, C, USA.

Patel, K. R.; Rademarcher, A. and Koch-Schulte, S. (2000). "Voices of the poor: Can anyone hear us?" In Sirwal, B.R. (ed). Empowerment of women: Conceptual framework. [online]. Available : http//www.scribed.com//doc/19166610/Empowerment-of-Women-onceptual-framework DA: 24/ $06 / 2011$

Nukunya, G. K. (2003). Tradition and change in Ghana: An introduction to sociology. (2nded). Accra: Ghana Universities Press.

Packer, C. A. A (2002). "Using human rights to change tradition: Traditional practices harmful to women's reproductive health in Sub- Saharan Africa."

Available: http//Error! Hyperlink reference not valid.. DA: 13/09/2009

Rahman, A. and Toubia, N. (2000).FGM: A guide to laws and policies worldwide. London, New York: Zed Books Ltd.

Tomasevski, T. (1991). Women and human rights. London, New York: Zed Books Ltd, Tsikata, D. (2000). Lip-Service and peanuts: State and national machinery for women in 
Africa. Accra: Third World Network Africa.

UNIFEM (2007). Violence against women: Facts and figures[online].

Available:http//www.unifem.org/attachments/gender issues/violence against women/facts figures violence against women 2007,pdf. DA:13/09/2009

Vijayamohanan, P. N.; Asalatha, B. P. and Ponnuswamy, B. (2009).” Women in Development: Dissecting the discourse"[online]. Available:

http//www.mpra.ub.uni.muenchen.de/women in developemnt the discource

WHO (2005). "Multi-country study on women`s health and domestic violence against Women: Summary report of initial results on prevalence, health outcomes and

Women`s responses." Geneva. World Health Organisation[online]. Available: http//www.who.intgender/violence/who_multicountry_study/en DA: 15/02/2012

Women's Manifesto Coalition (2004). A women`s Manifesto for Ghana Accra: Abantu for Development/WMC 